\title{
Are there any distributive effects of land title on labor supply? evidence from Brazil
}

\author{
Mauricio Jose Serpa Barros de Moura ${ }^{{ }^{*}}$, Marcos Ribeiro ${ }^{2}$ and Caio Piza ${ }^{3}$
}

\author{
* Correspondence: \\ mjmoura@gwmail.gwu.edu \\ 1320 S. West \#208, Alexandria, VA \\ 22314, USA \\ Full list of author information is \\ available at the end of the article
}

\begin{abstract}
This paper investigates the effects of land titling on labor supply for households heads. The effect of legal ownership security on the adult labor supply is identified by comparing the impact of being part of, or excluded from, a land title program in a unique public intervention in two neighboring communities in the Brazilian city of Osasco. We employ a quasi-experimental technique to identify the average treatment effect on treated by using diff-in-diff and ANCOVA methods. We also estimate distributive impact on the hours worked by adults by estimating unconditional quantile treatment effects. The results suggest that the impact of land titling on labor is positive and greater at the median of the "weekly hours worked" distribution.

JEL classification: numbers; J18; J22; K11 and R38

Keywords: Land titling; Labor supply; Average treatment effect; Quantile treatment effect
\end{abstract}

\section{Introduction}

Well-defined property rights are at the core of economic theory. Economic historians, such as North and Thomas (1973), North (1990) and Acemoglu and Robinson (2012), have shown the important role of property rights in economic development. Institutional economists, such as Coase, highlight the importance of well-defined property rights on the grounds of resource allocation efficiency. Mutually beneficial exchange would rarely take place in the absence of well-established property rights and enforcement mechanisms (Olson 1965, 2000).

More recently, development economists have shown how deleterious the lack of a formal property rights system can be for the poor. Banerjee and Duflo $(2008,2011)$ and Karlan and Appel (2011) thoroughly examine the problems of missing markets for the poor, their implications, and what can be done to fix them in an effective way. One of the most discussed problems of missing markets is the absence of credit markets for the poor. Sometimes it is not a lack of assets that prevent the poor from accessing credit, but the lack of well-defined property rights that could make those assets liquid and therefore accepted as collateral by lenders (Ray 1998).

In the same vein, de Soto (2000) argues that the lack of a property right system creates constraints for the poor to use their assets, e.g. land, as collateral to access credit markets (De Soto 2000). Many authors have argued that without access to credit the poor become more vulnerable to adverse shocks as they have access to limited and imperfect risk coping mechanisms (see Chambers 2006; Morduch 1994; Calvo and 
Dercon 2007). Perhaps land title is one way of helping the poor to smooth the effects of such shocks. This seems to be the case in Brazil. Piza and Moura (2011) analyze the same data used in this paper to assess the impact of having a land title on the use of credit. They find that land title increased access to and use of credit by 25 percentage points, with credit borrowed from formal banking institutions as the main driver of this result. There is some evidence that titled households may have used credit to consume durable goods, such as freezers and washing machines.

Despite the theoretical appeal, the impact of property rights on outcomes such as investment and access to credit is ultimately an empirical question. There is relevant literature that looks at the impact of property rights through the role of land title and tenure security (see Goldstein and Udry 2008; and Deininger and Feder 2009). This is exactly the approach used in this paper.

Most of the literature has focused on outcomes such as access to credit and investment (see Besley 1995, Field and Torero 2004; Carter and Pedro 2003; Galiani and Schargrodsky 2010; and Piza and Moura 2011), but only a few authors have turned their attention to second order effects, such as labor supply. As far as the authors of this paper are concerned, there is a limited sample of studies that apply experimental or quasi-experimental techniques to estimate the impact of land title on labor supply outcomes in urban areas of developing countries. Field (2007) looks at the impact of a massive land titling program in Peru on the labor supply (adult and child), whereas Moura and Bueno (2010) used quasi-experimental techniques to estimate the impact of a Brazilian land title program on the child labor supply.

In 2003, the federal government of Brazil announced a national plan to title 750,000 families. The program was designed to issue land titles to families living under illegal conditions (i.e., residents illegally squatting in urban dwellings). According to the most recent Brazilian annual household survey, about 5 percent of the country's households, or 10 million people, do not have tenure security (IBGE 2009). This particular land title plan only operates in illegally settled public areas. The main consequence is that new official property owners are fully protected under Brazilian Law. The government does not have any post rights over the land/property after titling execution. Other land dispute cases in Brazil are much more complex given that the invasion occurred on private property, which led to protracted legal battles as describes ANOREG (2007) manual report.

This paper contributes to the literature in different ways. It is the first investigation of the impacts of the Brazilian land-titling program on the adult labor supply. Such analysis can provide theoretical insights for titling programs and pro-poor spending in other developing and emerging economies. Secondly, the paper investigates whether the program had distributive impacts on the adult labor supply by estimating unconditional quantile treatment effects. To the best of our knowledge, potential distributional effects of a land-titling program on labor supply have never been studied. Finally, it is one of the few studies available in the empirical literature on land titles providing evidence of the impact of urban land titling programs.

We use fieldwork data from a public intervention that took place in one community of the Brazilian city of Osasco. In order to estimate the impact of the program, we collected baseline data in two neighboring communities and follow-up data one year later (March/ April 2007 and March/April 2008). Although the households of these communities are not 
entirely similar in observed characteristics, the design of the intervention left no space for self-selection, as all households in the treated community were given the title. Although drawing upon a framework more suitable under random allocation of the treatment, our difference-in-differences (DD) results passed several robustness checks.

Furthermore, our findings indicate that the land-titling program potentially had heterogeneous effects on the adult labor supply. We found a greater impact at the first two quartiles of the weekly hours worked distribution, which suggests, assuming the rankpreserving condition, a higher effect on adults who worked fewer hours prior to the intervention. Our results also contribute to the broader literature on land titling. Since the distribution of weekly hours worked was identical before the intervention, it is unlikely that the results are driven by reversion to the mean.

The rest of the paper is organized as follows. Section 2 outlines three potential mechanisms through which we argue land titling could increase the adult labor supply of squatter households. Section 3 discusses methodological issues, the data collected, and some descriptive statistics. Section 4 describes our empirical strategy. The empirical results are then discussed in Section 5. Lastly, Section 6 concludes the paper, offering some policy recommendations and proposing areas for future research.

\section{Mechanisms Overview}

This paper does not advocate for any specific mechanism, but outlines possible channels through which a land registration policy could positively affect adult labor supply. Note that these channels are not necessarily mutually exclusive.

Field and Torero (2004) show that titling efforts effectively increase household tenure security and should allow households and communities to reallocate time, resources, and human talent away from an informal policing role. The authors conclude that an exogenous increase in formal property protection should lower the opportunity cost of outside labor, increasing the hours worked outside the house and the likelihood of an improvement in the current income of those households.

Furthermore, Moura and Bueno (2010), used the same data and found that land-titling program decreased the intensive margin of child labor in about 5 hours per week.

Besley and Ghatak $(2008,2009)$, on the other hand, argue that most accurately defined rights to land affect the share of wealth that can be pledged as collateral in a credit contract. In this case, under certain conditions ${ }^{1}$ we can expect a positive effect from a land title program on access to credit though a higher share of collateralizable wealth. The credit could be used for durable goods acquisition (proxy for investment), non-durable consumption, or house improvement. Whatever the case, household members (adults) are expected to work extra hours to pay back the loan. If this is so, we could expect to see the poor working more extra hours than those who are better off.

In fact, Piza and Moura (2011) found some support for such a relation, as they found a positive effect on credit availability and on consumption of durable goods, such as household appliances. Using the same dataset, the authors show that use of credit increased by $6 \mathrm{pp}$. for the comparison group and by $32 \mathrm{pp}$. for the treated group. According to the authors, the average effect of land title on the probability of having had a formal bank loan was approximately $21 \%$, and the average impact on amount of working capital reached $72 \%$. 
The effect of durable goods on the adult labor supply is broadly documented in the applied literature of labor economics. It is argued that durable goods such as household appliances would save adults time in domestic work and allow them to work more hours outside the home. Since this paper draws on the same fieldwork data, the causal chain underlying the effect of land title on adult labor supply might be the same outlined in Piza and Moura (2011) more plausible mechanism in our case. Notice that if this is the channel through which tenure security affects labor supply, the program would very likely affect adults' weekly hours of work differently. Additional file 1: Tables S1 and S2 reproduce the Piza and Moura (2011)'s estimates on the impact of having a land title on the use of credit and on consumption of durable goods. The relatively large effect on acquisition of washing machine suggests that this might be one of the channels through which the intervention affected labor supply of the household head.

Another plausible mechanism assumes that a land title program is followed by a better supply of public goods such as security, electricity, garbage collection, and provision of a sewage connection (in the Osasco's case, immediately implementation of those public services were not part of the land title program. However, during several months after the titling, those services - each under a different timetable and dynamic - had started slowly to be part of the community's routine). The supply of public goods would therefore have positive externalities, such as increasing the housing value of a neighborhood ${ }^{2}$. In this scenario, a land title program could affect labor supply in two ways. Firstly, adults would have to work extra hours to pay their utility bills. Secondly, given the wealth effect that results from better access to public goods, the adult labor supply could increase or decrease, depending on whether leisure is a normal or inferior good ${ }^{3}$. If adults consider leisure a normal good, the effect of the intervention on their labor supply will be ambiguous since they would have to work harder to pay the bills, but due to the wealth effect they could demand more leisure.

Notice, however, that such context could confound the effect of the policy as some of the public goods could have a direct effect on the outcome of interest. If those could be expected to have a positive effect on the labor supply of the household head, the coefficient of the land title potentially would be upward biased.

On the other hand, if adults see leisure as an inferior good, they would work more hours. In this case, the wealth effect would not be large enough to cover extra expenses. Note that the distributive effect of the policy can be easily rationalized in this case as well. Given that the poor live in relatively cheaper houses, the wealth effect would be lower for them than for the better off. Because leisure is a good that is less affordable for the poor than for better-off households, poorer adults would respond to the intervention by working more hours than those who are better off. Based on available evidence, we would expect an increase in the adult labor supply.

\section{Methodological issues, data, and descriptive statistics}

This section discusses the sample used to evaluate the program, describes the dataset, and presents descriptive statistics of the program. Although we show that the neighborhoods are not entirely similar in observed characteristics, the design of the intervention left no space for participant self-selection for the program since all households from the selected community were given the title. For that reason, we believe that the main sources of bias of this intervention would come from the observed variables and, as suggested by the robustness of our estimates ${ }^{4}$. 


\section{(a) Minimizing selection bias concerns}

The Brazilian federal government chose Osasco as one of the cities for the Papel Passado titling program. Osasco has 30,000 people (about 6,000 families) living under informal conditions, which represents almost 4.5 percent of its total population (ANOREG 2007). The program timetable for Osasco establishes that all the communities (or favelas) living in illegal conditions should be part of the Papel Passado during the 2007 to 2014 period.

Yet, given Osasco's municipal budget constraints, not all of the communities received their land titles at the same time. The first locality to receive titles in 2007 was Jardim Canaã, where 500 families live (the median size of the titled land was 38 square meters. In Osasco, property tax is charged only for properties of more than 50 square meters. Thus, only 10 families began to pay property tax owing to the received title).

The closest neighborhood to Jardim Canã̃ is DR, home to 450 families. DR's households were scheduled to join the Papel Passado program in 2012. Such a particular geographic location provides a unique context for our analysis. For example, during the first semester of 2008 a new elementary school was built in the area. Households from both communities have benefited from this new public policy initiative. Further, Jardim Cana a and DR have similar economic and social characteristics. There is no physical border between the two neighborhoods since they are geographically contiguous, they are both located 2.5 miles from downtown Osasco, and they have precisely the same access to Osasco's main economic center. On the other hand, the geographical context increases the possibility of spillover effects (externalities of economic activity or processes that affect those who are not directly involved in Papel Passado).

This intervention procedure minimized the issue of self-selection in the program evaluation, as no households in Jardim Canaã that were given a land register as consequence of the intervention had received one before the intervention took place. In addition, 95 percent of the first survey participants-both from Jardim Canaz̃ and DR-did not expect to receive any land titles. They were neither aware of Papel Passado nor its meaning, reducing a potential behavioral deviation from households included in the program (anticipation bias). Randomization bias occurs, for example, when the need to recruit a greater number of applicants induces program administrators to change program admissions standards. A similar problem happens if individuals are aware of the randomized evaluation and choose not to apply to the program given the lower chance of receiving benefits. In both cases, results obtained from the evaluation may not be generalized to a context in which the program is not being implemented as a randomized trial (Heckman et al. 1997).

In turn, contamination bias is avoided given that the comparison group of residents cannot benefit from the program outside the treatment locality and there are no other land title programs in the region. Contamination bias could happen if members of the comparison group seek and receive alternative forms of treatment. This is usually a problem only when there are close substitutes for the program (Heckman et al. 1997).

Despite such a context, we found many differences in observable characteristics at the household level, as discussed below.

\section{(b) The Data}

We compare two neighboring communities in the Brazilian city of Osasco. This citywith around 654,000 inhabitants and nearly 6,000 families living informally-is located in the metropolitan area of São Paulo and is part of target area for Papel Passado. In 
one of its communities, Jardim Canaã, all households received land titles in 2007. In another, Jardim DR, the same program was implemented in 2012, making it a natural comparison group.

The dataset comprises results from a two-stage survey focusing on property rights. To minimize other potential biases, the survey questionnaire and researchers did not provide the households with any information on the research objectives. For those interviewed, the official subject of the study was general living conditions in Osasco.

The door-to-door questionnaire (answered by the household head only) consisted of 39 questions and was administered to a random sample of 326 families-185 from Jardim Canaa and 141 from $D R$. In many of its questions and methodologies, the survey instrument closely mirrored the content of the national statistical survey (Pesquisa Nacional de Amostra de Domicílios-PNAD) from the Brazilian Statistical Bureau (Instituto Brasileiro de Geografia e Estatística-IBGE). It asked a variety of questions on household and individual characteristics. Six additional questions were included to obtain information on a range of economic, social, and personal benefits associated with property ownership.

In March 2007, the first stage of the survey was conducted by researchers who were not originally from Osasco and before titles were issued to the households of Jardim Canaz̃. The second stage was implemented with surveys of the same households in 2008 (with 2 percent of the former interviewees missing) almost a year after the first titles were issued.

The study also tracked the households that moved away from both communities. In contrast to the 8 percent of households that moved away from Canaã after selling their properties (main reason to leave was the property sale or cash their new title by selling their houses), only 0.7 percent of households (1 out of 141) moved away from DR during the same period ${ }^{5}$.

Therefore, the structure of our dataset is a classical baseline and follow-up one year later. As discussed in McKenzie (2012), the ideal in this case would be to collect more follow-ups in shorter intervals, perhaps quarters. This approach would not only add to our understanding of the mechanisms underlying this intervention but would also make our identification strategy more convincing as it would increase the power of analysis, something desirable in cases in which the baseline may not add much information and in studies with a small sample size.

McKenzie (2012) recommends the ANCOVA estimator when the autocorrelation of the outcome of interest is lower than 0.5. He shows that in those cases "ANCOVA offers more power than either DD or the post estimator..." (p.8). It is also shown that in some circumstances involving a random intervention, the causal effect can be more precisely estimated without a baseline. In this paper we use the ANCOVA estimator as one of the robustness checks and show that in the present case the point estimate is very similar to the DD estimate. Fixed effects and random effects are provided for the sake of robustness. As with ANCOVA, the points estimates are very similar to the DD estimates.

\section{(c) Descriptive statistics}

Table 1 reports the T-test for the difference of means for a vector of covariates of the comparison and treatment groups in the baseline. Although residing in neighboring communities, the comparison of means suggests that many characteristics of treated 
and non-treated households differ, such as intensity of child labor, monthly income per capita, labor status, household size, education level of the family head, and wealth.

Given the pre-intervention difference in observables, we use the weighting function suggested by Hirano and Imbens (2001) to make the sample of treated and untreated more balanced. This approach was chosen because, apart from making the groups similar in terms of observables, it allows us to identify the unconditional quantile treatment effect of an intervention when the selection bias is due to observables (see Firpo 2007).

In addition, working with a balanced sample in the context of a two-period survey makes the parallel trend assumption in the DD framework more plausible when an intervention is not randomly allocated (see Heckman et al. 1997, Abadie 2005, Blundell and Dias 2002, and Smith and Todd 2005). In that sense, our approach resembles, for instance, that of Abadie (2005) who suggests a combination of matching and DD estimators. His approach is based on a weighting function to select groups with similar observable characteristics in the baseline when the intervention is not random. The DD is therefore estimated only when the sample is balanced.

The weighting function we use is given by,

$$
\hat{\omega}_{i}\left(\text { treat }_{i}, X_{i}\right)=\frac{\text { treat }_{i}}{\hat{p}\left(\text { treat }^{\prime}=1 \mid X_{i}\right)}+\frac{1-\text { treat }_{i}}{1-\hat{p}\left(\text { treat }=1 \mid X_{i}\right)}
$$

where treat $=$ treat $_{i}+\left(1-\right.$ treat $\left._{i}\right)$ is the treatment dummy and $\hat{p}\left(X_{i}\right)$ is the propensity score obtained from a logit regression model of the treatment on a constant and a vector $X$ that includes the household size, dummies for the household head's skin color, gender, marital status, and age and years of schooling.

The estimation of the propensity score did not include the other variables displayed in Table 2, because they might affect the selection of the treatment and might also be affected by the treatment status. Before weighting, the Hotelling test for the difference of means of the covariates of the treatment and comparison groups rejects the null of equal means at the 1 percent level $(F(7,297)=17.5)$. After weighting the sample, the

Table 1 T-test and Z-score for the difference of means for covariates, 2007

\begin{tabular}{llll}
\hline & $\begin{array}{l}\text { Mean } \\
\text { Comparison (A) }\end{array}$ & $\begin{array}{l}\text { Mean } \\
\text { Treatment (B) }\end{array}$ & $\begin{array}{l}\text { Test: A - B } \neq \mathbf{0} \\
\boldsymbol{p} \text {-value }\end{array}$ \\
\hline Gender (=1 if female) & 0.31 & 0.34 & 0.48 \\
Ethnicity (=1 if African-Brazilian) & 0.69 & 0.64 & 0.43 \\
Marital status (=1 if married) & 0.61 & 0.65 & 0.52 \\
Age & 42.6 & 39.4 & $0.06^{*}$ \\
Weekly hours of adult work & 10.1 & 10.4 & 0.81 \\
Weekly hours of child labor $>16$ years old) & 8.35 & 3.3 & $0.00^{* * *}$ \\
Years of education (family head) & 5 & 9 & $0.00^{* * *}$ \\
Monthly income (currency BRL ${ }^{9}$ ) per capita ${ }^{b}$ & 553.1 & 255.8 & $0.00^{* * *}$ \\
Informal worker (=1 if informal) & 0.94 & 0.65 & $0.00^{* * *}$ \\
Access to credit (=1 if have) & 0.44 & 0.45 & 0.88 \\
Number of children (<16 years old) & 0.78 & 0.81 & 0.46 \\
Observations (households) & 168 & 137 & \\
\hline
\end{tabular}

Source: Research from the Osasco Land Title Survey and Central Bank of Brazil

Notes: ${ }^{*}{ }^{* *},{ }^{* *}$ rejection of the null hypothesis of equal mean significant at 10,5 , and 1 percent, respectively.

${ }^{a}$ Currency exchange rate on 12/31/2008: 1 USD $=1.75$ BRL (Brazilian reais).

${ }^{b}$ Monthly income per capita is calculated dividing monthly income by the number of residents. 
Hotelling test fails to reject the null $(F(7,297)=0.97)$. Figure 1 shows the Kernel density distributions of the propensity score after weighting. As can be seen, there is considerable overlap between density distributions of the propensity scores of both groups. Thus, there is no need to trim the distribution of the propensity score to select the common support.

\section{Empirical strategy}

The previous section showed some statistically significant differences between covariates of the treated and untreated groups. These differences can be attributed to the fact that the selection of the two groups was not based on household characteristics but on the similarities of the communities.

Berhman and Todd (1999) demonstrate that for the Mexican conditional cash transfer program Progresa/Oportunidades, although the control and treatment neighborhoods randomly selected to participate in the program are similar in terms of observables at the community level, they are not fully comparable at the household level. They suggest the use of control variables in a double difference estimation to control for differences in observables (see e.g. Skoufias and Parker 2001 for an empirical evaluation of the program).

Our empirical strategy draws on the quasi-experimental literature, as it is based on the application of the DD and the unconditional quantile treatment effect estimators as the selection of the treatment neighborhood seems to be based on observable characteristics. The estimate of the unconditional quantile treatment effects (QTE) allows us to look for the distributional effects of the intervention in a much more flexible way than the traditional quantile regression (QR) method (see Buschinsky 1998 for a survey on $\mathrm{QR}$, and on the pros of unconditional methods).

The DD model is estimated as follows ${ }^{6}$ :

$$
H_{i t}=\beta_{0}+\beta_{1} \text { treat }_{i}+\beta_{2} \text { year }_{t}+\alpha_{D D} \text { treat }_{i} * \text { year }_{t}+u_{i t}
$$

where $H_{i t}$ is the weekly number of hours worked by the household head $i$ at time $t$; treat $_{i}$ is a dummy variable that takes the value of 1 if the individual resides in the treated community, and 0 otherwise. Note that once all households of the eligible community are effectively treated (perfect compliance), there is no difference between eligibility and treatment status. The year $_{t}$ dummy takes the value of 0 in 2007 (baseline period) and 1 in 2008. We do not control for other covariates, because we will fit the model in a balanced sample. Finally, $u_{i t}$ denotes the error term that is assumed to be independent of the covariates as long as the sample is balanced.

Table 2 Land title impact on labor supply (Pre Program), 2007

\begin{tabular}{lll}
\hline Variables & Model 1 & Model 2 \\
\hline Land title & 0.36 & 0.69 \\
& $(1.42)$ & $(1.99)$ \\
Controls & No & Yes \\
Observations & 305 & 305 \\
R-squared & 0.00 & 0.17 \\
\hline
\end{tabular}

Notes: Clustered standard errors in parenthesis. The controls include the head's gender (female), skin color (white), marital status (married), age and age squared, household size, head's years of schooling, wealth index and labor market status (informal). 


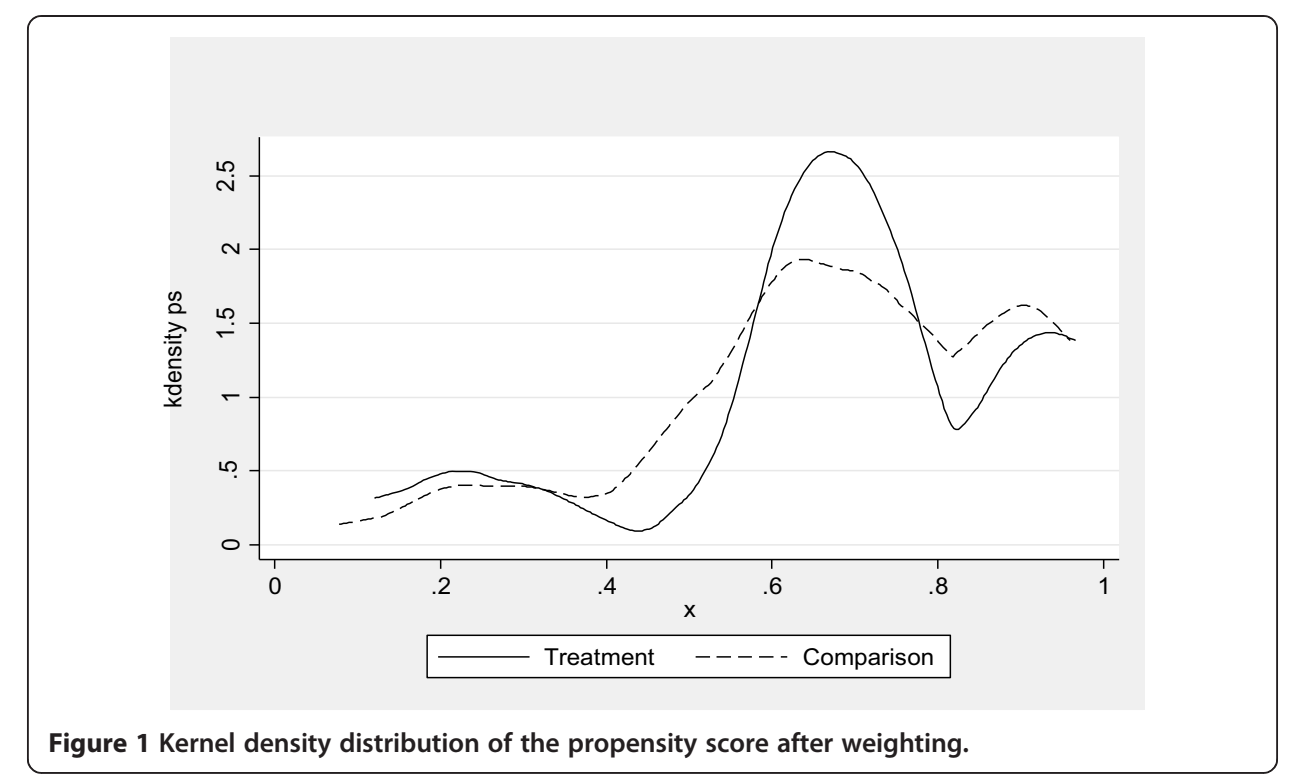

Our parameter of interest is the coefficient $\alpha_{D D}$, which identifies the effect of the treatment on the treated group. The causal interpretation of the parameter $\alpha_{D D}$ relies on the assumptions that (i) selection for the treatment does not depend on unobservable individual and community characteristics changing over time and (ii) the difference between the treated and comparison groups would be the same in the absence of the program (i.e., there is a time-invariant common effect).

The main issue regarding (2) is anticipation bias. This would certainly be an issue if household heads decided to work more hours given the expectation of receiving land title in the future. However, as mentioned above, only 5 percent of those interviewed had heard about the program. Regarding assumption (ii), we use a balanced sample to account for differences in observed characteristics between the two groups at the baseline to make the common trend assumption more plausible in the DD context (Abadie 2005). In addition, the fixed effect estimator is applied to check the robustness of the results given that the individuals and communities can differ in terms of time-invariant unobserved characteristics.

To check for any distributional effects of the intervention, we estimate the QTE as proposed by Firpo (2007) as it deals perfectly with the selection bias problem in our sample (selection on observables). Many authors have argued that it is important to look at the impact of an intervention at different points of the outcome distribution (see Koenker and Hallock 2001). For instance, Frölich and Melly (2008) show that the distribution of a dependent variable may change in many ways that are not completely revealed by an examination of averages; one of the advantages of estimating unconditional QTE is that it does not depend on any particular value of the covariates.

Another advantage of QTE methods relative to the common effect model is that the impact of the program on different quantiles of the outcome distribution does not have to be constant. For any fixed percentile, QTE corresponds to the horizontal distance between two cumulative distribution functions. QTE is a powerful and intuitive tool that allows researchers to discover the effects an intervention on the entire distribution of the outcome of interest ${ }^{17}$. 
Comparing the conditional and unconditional regression methods, Frölich and Melly (2008) argue that the unconditional QTE estimator has at least three main advantages over the conditional QR. Firstly, as mentioned, the definition of the unconditional QTE does not alter when a set of covariates changes. In other words, the point estimate does not depend on the $X$ vector. Secondly, unconditional effects can be estimated consistently at rate $\sqrt{ } n$ without any parametric restrictions, which is impossible with the conditional quantile estimator. Thirdly, the effects on the entire population are often more interesting for policy-makers than a large number of effects for different covariate combinations.

It is important to bear in mind, however, that the quantile regressions (conditional or unconditional) do not tell us anything about the effect of a policy/treatment on individuals (or households). In fact, they only inform us as to whether the effect of the treatment is different at distinct points of the outcome variable distribution. In other words, if the coefficient of the first decile is higher than the coefficient of the top decile, this does not mean that individuals in the first decile were more affected by the treatment. That coefficient merely tells us that the effect is higher at the lower tail of the outcome variable distribution. However, by assuming that the intervention does not change the households' ordering in terms of the outcome variable distribution, then one can argue that the impact is higher amongst the individuals in the lower tail of the outcome variable distribution. This assumption is known as rank-invariance or rank-preserving.

The estimation procedure of the QTE can then be described as follows. Let $H_{i}(1), H_{i}(0)$ be the potential outcome for a household $i . H_{i}(1)$ would be realized if household $i$ were to receive the treatment 1 (land title) and $H_{i}(0)$ would be realized otherwise. The observed outcome, $H_{i}$, is equal to $H_{i}=H_{i}(1)$ treat $_{i}+H_{i}(0)\left(1-\right.$ treat $\left._{i}\right)$. Hence, the main objective of our quantile regression is to estimate the entire distribution function of $H(1)$ and $H(0)$.

The unconditional QTE (for quantile $\tau$ ) is given by:

$$
\Delta^{\tau}=Q_{H(1)}^{\tau}-Q_{H(0)}^{\tau}
$$

The particular case of the land title program in Osasco can be qualified as an unconditional QTE with exogenous treatment. Melly (2006), Firpo (2007), and Frölich (2007) provide different econometric methods to deal with such a case. Here, we follow Firpo (2007) and estimate the QTE in two steps. In this method, under the conditions of (i) ignorability of treatment, (ii) common support, and (iii) existence of quantile monotonicity, estimating the QTE is possible by using the weighting estimator of the checkfunctions. When the sample is not well-balanced in terms of observable characteristics, the weighting function depends on a propensity score estimated in the first step. In fact, we already have a balanced sample based on this weighting scheme.The following QTE estimator is then proposed:

$$
\widehat{\Delta q}_{\tau}=\underset{\alpha, \Delta}{\operatorname{argmin}}\left\{\frac{1}{N} \sum_{i=1}^{N} \hat{\omega}_{i}\left(\text { treat }_{i}, X_{i}\right) \rho_{\tau}\left(H_{i}-\alpha-\Delta \text { trea }_{i}\right)\right\},
$$

where $\rho_{\tau}(\cdot)$ are the check-functions. Firpo (2007) suggests a non-parametric estimation of the propensity score (local logit). Given the limited size of our sample, we estimate 
the propensity score parametrically applying a logit model as already discussed. Thus, the weight function, $\omega(\cdot)$, used to identify the unconditional quantile treatment effects is computed with the propensity score estimated parametrically. Following Firpo (2007), the QTE estimates are not restricted to the common support provided the sample is balanced.

\section{Results}

This section presents the results of the empirical analysis proposed in the previous section. We start by discussing the findings of the analysis for the mean. Then we consider the distributive effects estimated via the QTE methods.

Table 2 presents the estimation results of the empirical model for the baseline year 2007. In that year, Papel Passado had not yet been implemented and no household had received land title. The estimations, including (and excluding) the control variables, find no significant impact of land title on the number of hours worked weekly. As expected, the fact of whether or not a household belonged to the treated neighborhood before the program took place did not lead to a statistically significant difference in the number of hours worked. Prior to the program, the incentives to increase labor supply due to land title were weak, reducing the possibility of anticipation bias among the titling program participants.

Table 3 presents a set of estimates, including the ANCOVA. For all regressions we use clustered standard errors to control for potential correlation among units in each community. The first column shows the OLS estimate controlling exclusively for the dependent variable lagged for one period. The land title coefficient is very precisely estimated and suggests that an adult from Jardim Canã̃ worked about 8 hours/week more than a resident of $D R$ due to the intervention, or about 1.2 hours of work per day if we consider that residents of these communities usually work six days per week. When we include controls, the point estimate remains almost the same, but there is a slight increase in precision. This is a positive result, as it shows that the omitted variables are not driving the results. Taking the pre-treatment average of hours worked in

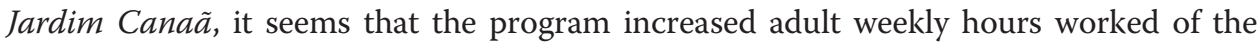
treated in about 80 percent of households.

We then run the DD estimates. Again, we start with a specification excluding the controls. The fourth column shows that the DD estimate is precisely estimated, but it

Table 3 OLS estimates land title impact on labor supply (Post-Program), 2008

\begin{tabular}{lllllll}
\hline \multirow{2}{*}{ Variables } & Model 1 & Model 2 & Model 3 & Model 4 & Model 5 & Model 6 \\
\hline Land title & ANCOVA & ANCOVA & ANCOVA Tobit & DD OLS & DD OLS & DD Tobit \\
& $7.96^{* * *}$ & $7.69^{* * *}$ & $10^{* * *}$ & $7.15^{* * *}$ & $6.92^{* * *}$ & $12^{* * *}$ \\
Lagged Y & $(0.05)$ & $(0.4)$ & $(3.1)$ & $(2.32 \mathrm{e}-14)$ & $(0.3)$ & $(1.44)$ \\
\hline A. Matched sample? & No & Yes & Yes & No & No & No \\
\hline Pseudo-R2/R2 & 0.10 & 0.20 & 0.17 & No & Yes & Yes \\
Observations & 305 & 305 & 194 & 0.1 & 0.21 & 0.04 \\
\hline
\end{tabular}

Notes: Clustered standard errors are in parentheses. ${ }^{*},{ }^{* *},{ }^{* * *}$ Statistically significant at 10, 5, and 1 percent Statistically significant at 10,5, and 1 percent respectively. The controls include the head's gender (female), skin color (white), marital status (married), age and age squared, household size, head's years of schooling, wealth index and labor market status (informal). 
is slightly lower in magnitude than the ANCOVA, pointing to an impact of seven extra hours worked per week. Including the controls, the point estimate remains around seven and once again there is an improvement in precision. In relative terms, the DD estimate is ten percent points lower than the ANCOVA estimate.

Because there are many adults with zero hours worked at the baseline, we also estimate a Tobit model. The third model in column 3 controls for the dependent variable in the baseline and the other covariates. As expected, when we take into consideration the censored characteristic of the outcome variable, the point estimate jumps to ten and loses precision but remains significant at the 1 percent level. The Tobit DD estimate is still higher, pointing to an impact of Papel Passado of 12 extra hours worked per week, or about 2 extra hours of work per day in a week with six working days (which basically means one hour more during the morning and one hour more during the afternoon). In relative terms, this coefficient is 20 percentage points higher than the ANCOVA Tobit estimate. The DD Tobit estimate is statistically different from the other DD estimates and is very precisely estimated. It is therefore used as the benchmark estimate of the average treatment effect on the treated (ATT) of this intervention.

The impact of the program on the intensive margin of labor supply of the household head might be capturing extra hours of work of individuals who entered the labor force after receiving the land title. To check whether that was the case, estimate for the extensive margin is provided with participation rate taking the value of 1 if weekly hours worked is greater than zero and 0 otherwise.

Table 4 shows the results for participation rate and participation rate in the informal sector. The point estimates are positive, large and precisely estimated for the fixed effect model. Interpreting the coefficients as ATT, the program increased participation rate in 31 percentage points. Two thirds of the impact was in the informal sector. The impact of the program on the extensive margin of labor supply of the household head might be explained either because some decided to run their own business as now they seem to be able to access credit market or because the acquisition of time saving durable goods such as wash machines or a combination of the two ${ }^{7}$.

Estimating the impact of the program for those already in the labor force at the baseline, we find no impact at the intensive margin of labor supply. Table 5 shows the results. Thus, the impact on weekly hours worked presented in table 3 is completely driven by the effect of the program on participation rate.

\section{(a) Distributive effects of land title programs}

This subsection presents the findings of the distributive empirical analysis. Before discussing the results of the QTE analysis, we start by looking for evidence of distributive effects using first-order stochastic dominance analysis.

Figure 2 shows the result of this analysis for the pre-treatment year (2007). It shows that the distribution of adults' weekly hours worked for the treatment group level does not dominate, in the first degree, the distribution of adults in the comparison group at the baseline.

Yet, Figure 3 shows that the distribution of weekly hours worked in the comparison group is first-order stochastic-dominated one year after the intervention. This preliminary analysis indicates that the land title program positively affected the whole cumulative distribution of weekly hours worked, not only the average. 
Table 4 Difference-in-difference estimates: impact of having a land title on the extensive margin of labor supply

\begin{tabular}{|c|c|c|c|c|c|c|c|c|}
\hline & \multicolumn{4}{|c|}{ DD } & \multicolumn{4}{|c|}{$\mathrm{FE}$} \\
\hline & LFPR & LFPR & Informal & Informal & LFPR & LFPR & Informal & Informal \\
\hline \multirow[t]{2}{*}{ Title*Post } & $0.31^{* * *}$ & $0.31^{* *}$ & $0.22^{* * *}$ & 0.21 & $0.31^{* * *}$ & $0.31^{* * *}$ & $0.22^{* * *}$ & $0.21^{* * *}$ \\
\hline & $(3.91)$ & $(2.22)$ & $(2.74)$ & $(1.57)$ & $(8.65)$ & $(8.65)$ & (5.83) & $(5.71)$ \\
\hline \multirow[t]{2}{*}{ Title } & -0.043 & -0.019 & $-0.16^{* * *}$ & -0.12 & $\mathrm{Na}$ & $\mathrm{Na}$ & $\mathrm{Na}$ & $\mathrm{Na}$ \\
\hline & $(-0.74)$ & $(-0.19)$ & $(-2.84)$ & $(-1.22)$ & $\mathrm{Na}$ & $\mathrm{Na}$ & $\mathrm{Na}$ & $\mathrm{Na}$ \\
\hline Matched sample & No & Yes & No & Yes & No & Yes & No & Yes \\
\hline Adjusted R2/Within R2 & 0.061 & 0.064 & 0.018 & 0.015 & 0.307 & 0.307 & 0.138 & 0.141 \\
\hline Observations & 610 & 610 & 610 & 610 & 610 & 610 & 610 & 610 \\
\hline
\end{tabular}

Note: Clustered standard errors are in parentheses. ${ }^{*}, *^{* * * *}$ Statistically significant at 10,5 , and 1 percent respectively.

\section{(b) Quantile treatment effects}

Turning to the QTE estimation, Table 6 shows the quantile point estimates in the three quartiles and in the top decile of the weekly hours worked distribution, whereas Figure 4 compares the QTE point estimates with the DD Tobit estimate.

Table 6 suggests that the impact of land titling is higher in the first half of the outcome variable distribution. According to the estimates, the impact of the land title is significant in the first, second, and third quartiles. The impact on the first quartile points to an impact of the intervention of around 12 extra worked hours per week-an effect that is equal to that obtained with the DD Tobit model discussed above. The impact on the third quartile is about seven and is therefore in line with some of the ATT estimates (see Table 3). The largest impact is on the median, 25 hours worked per week, showing that (i) some outliers, mainly in the lower tail of weekly hours worked distribution, may be driving the ATT results, and (ii) that the intervention seems to have had distributional effects. This is the only point estimate that is statistically different from the DD Tobit. This result is significant, as it means an impact of more than four extra hours of work per day for an adult who works six days per week, or more than three hours a day for someone who works seven days per week. Considering the median of the subsample of Jardim Canañ, which reported positive weekly hours worked at the baseline (20), the estimate at the median represents an increase of 125 percent in weekly hours of work. Assuming rank-preservation, i.e., that the program did not alter the order of adults in the hours-worked distribution, this higher impact in the first two quartiles was among adults who worked less before receiving the title.

Table 5 Difference-in-difference estimates: impact of having a land title on the intensive margin of labor supply, subsample of household heads in the labor force

\begin{tabular}{lllll}
\hline & DD & & FE & \\
\hline Title*Post & 1.62 & 1.76 & 0.67 & 0.81 \\
& $(0.83)$ & $(0.80)$ & $(0.61)$ & $(0.68)$ \\
Title & $2.78^{* *}$ & $2.95^{*}$ & $\mathrm{Na}$ & $\mathrm{Na}$ \\
& $(2.04)$ & $(1.86)$ & $\mathrm{Na}$ & $\mathrm{Na}$ \\
Adjusted R2/Within R2 & 0.07 & 0.08 & 0.11 & 0.11 \\
Observations & 336 & 336 & 336 & 336 \\
\hline
\end{tabular}

Note: Clustered standard errors are in parentheses. ${ }^{*}, * * * * *$ Statistically significant at 10,5 , and 1 percent respectively. 


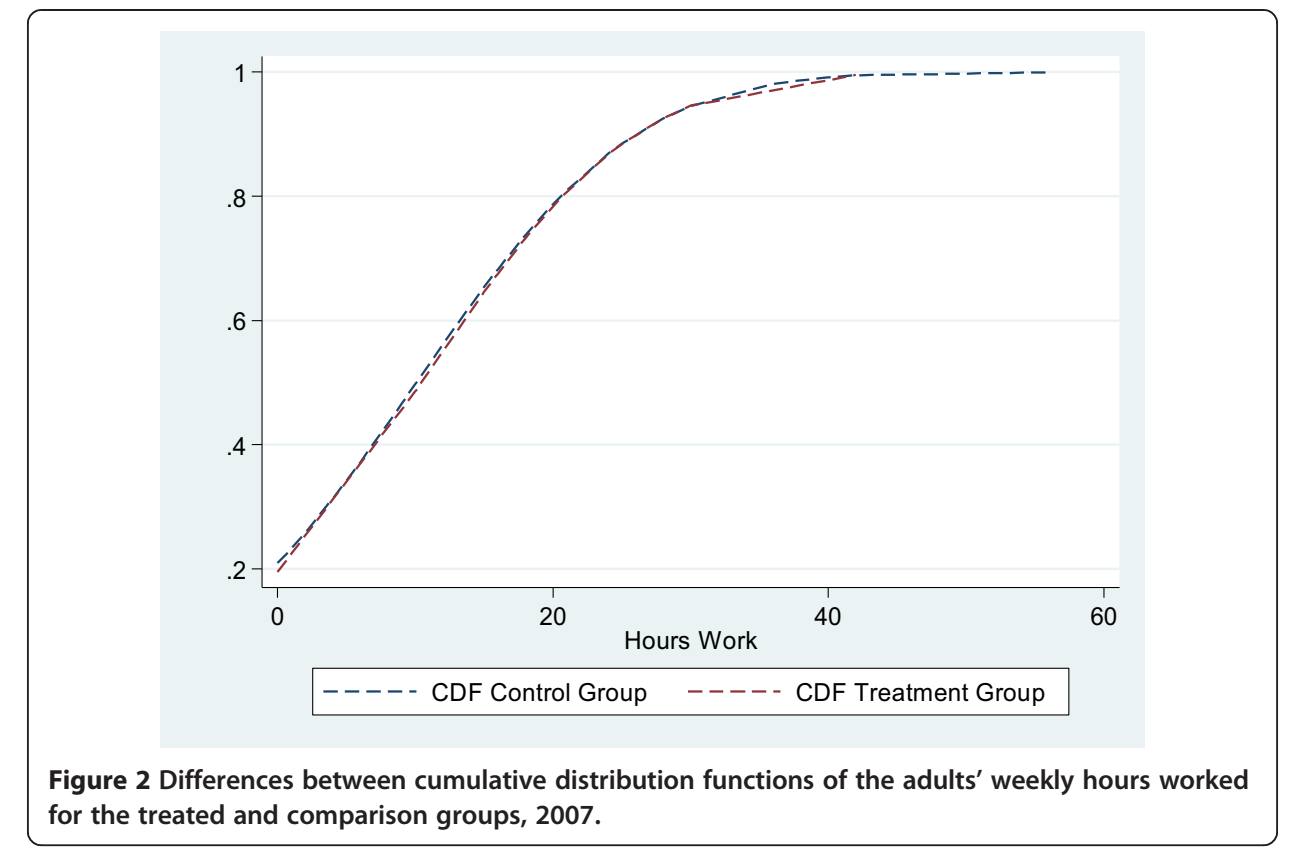

We should interpret the high impact on the lower tail of the hours-worked distribution with some caution. A mean reversing problem could be a possible explanation for the high impact on the lower tail. The baseline characteristics show that the treatment group has a higher education level but lower current income than the comparison group. Thus, the higher impact on the first quantiles may suggest some reversion to the mean, as one would expect better-educated people to have higher incomes. However, one could argue that although the correlation between earnings and years of schooling tends to be high, this might not be the case when we are dealing with the income and education of selfemployed people with a low stock of human capital-due not only to fewer years of schooling, but also to the probable low quality of the schools these people attended.

We believe that this set of estimates provides reliable evidence of the distributive effect of the program, since the intervention left no room for individual self-selection for the program. The upper tail of the outcome distribution presents the positive effect of land title on labor supply even though the coefficient is not statistically significant. The point estimates are very similar in magnitude to the ANCOVA estimates. Our results suggest that the QTE estimates of this intervention are heterogeneous and more concentrated around the median. Completely in line with the literature, the results suggest that property rights matter even more for the poor than for those with higher incomes.

The main implication of our empirical analysis is that the Brazilian land titling program had a positive effect on hours worked and labor supply among adults. While the ANCOVA and DD estimates point to the positive effects of land titling on the average number of weekly hours worked, the QTE method points to a distributive effect of the intervention, mainly at the median of the unconditional distribution of outcome variables. However, the estimates for the extensive margin of labor supply strongly suggest that the effect on hours worked is driven by the increase in participation rate since the coefficients for the ATT and QTE become small statistically insignificant once we condition the distribution on those already in the labor force at the baseline. 


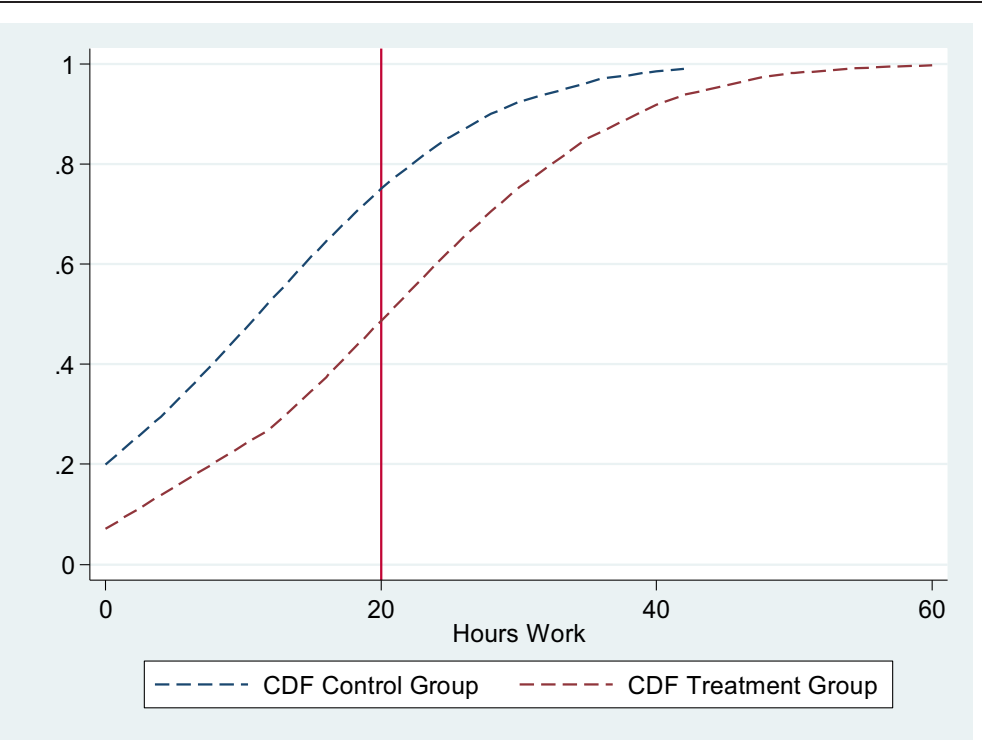

Figure 3 Differences between cumulative distribution functions of the adults' weekly hours worked for the treated and comparison groups, 2008.

As Section 2 suggests, one explanation for this finding is that the land title provides property security, particularly for those households most excluded from the labor market. That security enables these householders to search for, and find, occupations, instead of staying at home protecting their property. Thus, our findings also indicate the relevance of such titling programs for the poorest urban households in developing countries.

Two additional implications can be drawn from the quantile (distributive) analysis. Firstly, these heterogeneous effects should be taken into account by authorities designing public policies. The quantile analysis suggests that the impact of the policy (in this case, land titling) can be significant economically and statistically only in a certain range of the outcome variable's distribution; therefore, such programs are very likely more suitable for a specific group of people. Assessing the distributive impacts of the policy would help authorities to target their policies better, improving their effectiveness.

\section{Conclusion}

This paper offers new evidence on the value of formal property rights in urban squatter communities. Empirically, the study provides additional support for the finding

Table 6 Unconditional quantile treatment effect estimates, 2008

\begin{tabular}{llllll}
\hline Variables & $\mathbf{( 0 . 1 0 )}$ & $\mathbf{( 0 . 2 5 )}$ & $\mathbf{( 0 . 5 0 )}$ & $\mathbf{( 0 . 7 5 )}$ & $\mathbf{( 0 . 9 0 )}$ \\
\hline Whole Sample: & & & & & \\
Land Title & - & $12.00^{* *}$ & $25.00^{* * *}$ & $7.54^{* * *}$ & 7.64 \\
& - & $(5.33)$ & $(1.88)$ & $(3.15)$ & $(5.11)$
\end{tabular}

Observations

Whole Sample

305

305

305

305

305

Notes: Standard errors (in parenthesis) are computed with the algorithm (2009). ${ }^{*},{ }^{* *},{ }^{* * *}$ Statistically significant at 10,5 , and 1 percent, respectively. Using a T-test, it can be checked if the quantile estimates are statistically different from 0 . For instance, the T-test for the difference between the coefficients in the third and second quartiles in the first row can be computed as $t=\frac{25-12}{\sqrt{ }(5.3)^{2}+(1.9)^{2}} \cong 2.3$. 


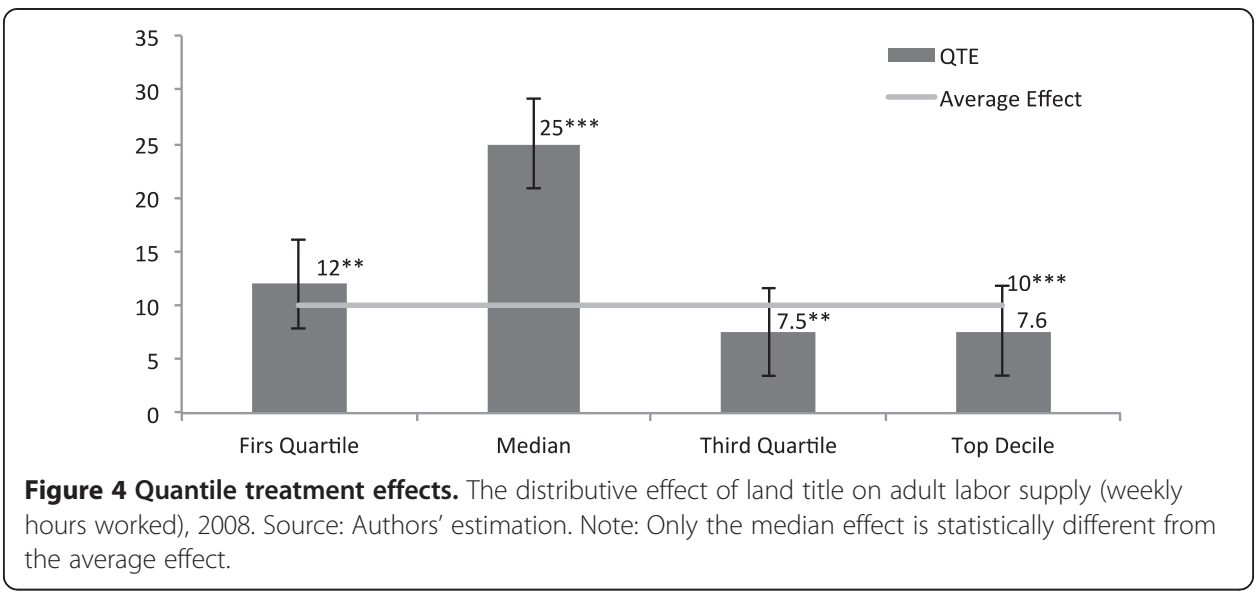

that property titling constitutes an incentive for labor supply, increasing participation rate and hours worked weekly. Under rank preserving condition, the QTE estimates indicate that the poorest households appear to benefit most from formal property rights. Such findings could not have been investigated using a simple mean estimation analysis.

The results also have potential implications for understanding labor market participation and friction (Goldsmith 1995), and for designing better pro-poor spending in emerging economies and developing countries.

This analysis offers various possibilities for further research. For example, the effects on the income and utility of households of the increase in the number of hours worked via the land titling program could be better investigated. At this stage, the income gain for households from increasing their labor force participation is not clear. Positive impact is found for use of credit, consumption of time saving durable goods and participation rate primarily in informal occupations.

Although more than one mechanism could explain the results, the estimates support a theory of change that links land title and labor market outcomes through two intermediary outcomes: use of credit and consumption of durable goods.

Finally, the distributional impact of land titling on other economic variables such as access to credit and fertility could also be analyzed. This would improve the assessment of the effects of such programs on the lives of the millions of households in urban squatter communities in developing and emerging economies worldwide.

\section{End notes}

${ }^{1}$ Deininger and Feder (2009) argue that the effect of land title on access to credit depends on the existence of credit and land markets, and on enforceability mechanisms.

${ }^{2}$ It is worth emphasizing that spillover effects could be a problem in our case since the treated community, Jardim Canaã, is geographically very close to the control one.

${ }^{3}$ It could be seen as an increase in the non-labor income. The literature on labor supply usually considers the non-labor income having a positive impact on leisure demand.

${ }^{4}$ Since we have two points in time and an imbalanced sample at the baseline, we follow Abadie (2005) who argues that matching the sample at the baseline makes the parallel trend assumption in the difference-in-difference framework less strong in this case. 
${ }^{5}$ We approach the attrition problem by matching the sample at the baseline of all individuals we observe in both periods.

${ }^{6} \mathrm{We}$ also estimate the impact based on a specification with the dependent variable one period lagged as an additional regressor (ANCOVA estimator).

${ }^{7}$ In fact, there is an indication that the program affected intra-household time allocation. Using the same dataset, Moura and Bueno (2010) found that the program reduced child labor.

\section{Additional file}

Additional file 1: Table S1. Impact of Having a Land Title on the Use of Credit. Table S2. Difference-in-

Difference Estimates for the Impact of Having a Land Title on Consumption of Durable Goods.

\section{Competing interest}

The IZA Journal of Labor and Development is committed to the IZA Guiding Principles of Research Integrity. The authors declare that they have observed these principles.

Responsible editor: David Lam

\section{Author details}

${ }^{1} 320$ S. West \#208, Alexandria, VA 22314, USA. ${ }^{2} 700$ 19th Street, N.W., Washington, DC 20431, USA. ${ }^{3} 1600$ South Eads Street, 415 S, Arlington, VA 22202, USA.

Received: 19 January 2014 Accepted: 7 May 2014

Published: 30 Jun 2014

\section{References}

Abadie A (2005) Semiparametric Difference-in-Differences Estimators. Review of Economic Studies 72(1):1-19

Acemoglu D, Robinson JA (2012) Why Nations Fail: The origins of power, prosperity, and poverty. Crown Business, New York

Associação dos Notários e Registradores do Brasil (2007) Publicação Anual 2007. Author, Sao Paulo, Brazil. http://www. anoreg.org.br/. Accessed March 2008

Associação Nacional dos Registradores do Estado de São Paulo (2007) Sistema de Biblioteca. Cartilha dos Registros Públicos. (No.Ill, pp.03-05). Author, Sao Paulo, Brazil. http://www.anoreg.org.br. Accessed 15 March 2011

Banerjee AV, Duflo E (2008) The Economic Lives of the Poor. Journal of Economic Perspectives 21(1):141-167

Banerjee AV, Duflo E (2011) Poor Economics: A radical rethinking of the way to fight global poverty. Public Affairs, New York

Berhman JR, Todd P (1999) Randomness in the Experimental Samples of PROGRESA. In: Report Submitted to PROGRESA. International Food Policy Research, Washington DC

Besley T (1995) Property Rights and Investment Incentives: Theory and Evidence from Ghana. The Journal of Political Economy 103(5):903-937

Besley T, Ghatak M (2008) Creating Collateral: The de Soto Effect and the Political Economy of the Legal Reform. In: London School of Economics, Working Paper, March

Besley T, Ghatak M (2009) The de Soto Effect. In: London School of Economics, Working Paper, April

Blundell R, Dias MC (2002) Alternative Approaches to Evaluation in Empirical Microeconomics. In: IFS working paper CWP10/02

Buschinsky M (1998) Recent Advances in Quantile Regression Model: A Practical Guideline for Empirical Research. The Journal of Human Resources 33(1):88-126

Calvo C, Dercon S (2007) Vulnerability to Poverty. CSAE WPS/2007-03.

Carter M, Pedro O (2003) Getting Institutions Right for Whom? Credit Constraints and the Impact of Property Rights on the Quantity and Composition of Investment. American Journal of Agricultural Economics 85:173-186

Chambers R (2006) Vulnerability, Coping and Policy. IDS Bulletin 37(4):33-40

De Soto H (2000) The Mystery of Capital. 32-38 Basic Books, Editora Record, Brazil

Deininger K, Feder G (2009) Land Registration, Governance, and Development: Evidence and Implications for Policy. The World Bank Research Observer 24(2):233-266

Field E (2007) Entitled to Work: Urban Property Rights and Labor Supply in Peru. The Quarterly Journal of Economics 122(4):1561-1602

Field E, Torero M (2004) Do Property Titles Increase Credit Access Among the Urban Poor? Evidence from Peru. In: Research Program in Development Studies Working Paper No. 223, Princeton University

Firpo S (2007) Efficient Semiparametric Estimation of Quantile Treatment Effects. Econometrica 75(1):259-276

Frölich M (2007) Propensity Score Matching Without Conditional Independence Assumption with an Application to the Gender Wage in the UK. Econometrics Journal 139:35-75

Frölich M, Melly B (2008) Unconditional Quantile Treatment Effects Under Endogeneity. In: IZA Discussion Paper No. 3288 , January

Galiani S, Schargrodsky E (2010) Property Rights for the Poor: Effects of Land Titling. Journal of Public Economics 94(9-10):700-729 
Goldsmith AA (1995) Democracy, Property Rights and Economic Growth. Journal of Development Studies 32(2):157-174

Goldstein M, Udry C (2008) The Profits of Power: Land Rights and Agricultural Investment in Ghana. Journal of Political Economy 116(6):981-1022

Heckman J, Hotz J, Ichimura H, Todd PE (1997) Matching as an Econometric Evaluation Estimator: Evidence from Evaluating a Job Training Program. Review of Economic Studies 64(4):605-654

Hirano K, Imbens GW (2001) Estimation of causal effects using propensity score weighting: an application to data on right heart catheterization. Health Services and Outcomes Research Methodology 2(3-4):259-278

IBGE (2009) Pesquisa Nacional por Amostra de Domicilios (PNAD).

Karlan D, Appel J (2011) More Than Good Intentions: How a new economics is helping to solve global poverty. Dutton, Penguin Group, New York, NY

Koenker R, Hallock KF (2001) Quantile Regression. Journal of Economics Perspectives 5(4):143-156

McKenzie D (2012) Beyond Baseline and Follow-up: The case for more T in experiments. Journal of Development Economics 99(2):210-221

Melly B (2006) Estimation of Counterfactual Distributions Using Quantile Regression. In: Swiss Institute for International Economics and Applied Economic Research (SIAW). mimeo

Morduch J (1994) Poverty and Vulnerability. American Economic Review Papers and Proceedings 84(2):221-225

Moura MJSB, Bueno R (2010) Some Notes on How Land Title Affects Child Labor? Revista da ANPEC 11(2):357-382 North DC (1990) Institutions, Institutional Change and Economic Performance. Cambridge University Press, Cambridge North DC, Thomas RP (1973) The Rise of the Western World: A New Economic History. Cambridge University Press, Cambridge

Olson M (1965) The Logic of Collective Action: Public Goods and the Theory of Groups. Studies, Harvard Economic Olson M (2000) Power and Prosperity: Outgrowing Communist and Capitalist Dictatorships. Basic Books.

Piza C, Moura M (2011) How Does Land Title Affect Access to Credit? Empirical Evidence from an Emerging Economy. In: Working Paper Series 2211, Department of Economics, University of Sussex

Ray D (1998) Development Economics. Press, Princeton University

Skoufias E, Parker SW (2001) Conditional cash transfers and their impact on child work and schooling: Evidence from the Progresa Programme in Mexico. Economia, Fall, pp 45-96

Smith JA, Todd PE (2005) Does Matching Overcome LaLonde's Critique of Nonexperimental Estimators? Journal of Econometrics 125(1-2):305-353

10.1186/2193-9020-3-11

Cite this article as: de Moura et al: Are there any distributive effects of land title on labor supply? evidence from Brazil. IZA Journal of Labor \& Development 2014, 3:11

\section{Submit your manuscript to a SpringerOpen ${ }^{\circ}$ journal and benefit from:}

- Convenient online submission

- Rigorous peer review

- Immediate publication on acceptance

Open access: articles freely available online

- High visibility within the field

Retaining the copyright to your article

Submit your next manuscript at $\boldsymbol{~ s p r i n g e r o p e n . c o m ~}$ 